\title{
OPEN The beneficial effects of menopausal hormone therapy on renal survival in postmenopausal Korean women from a nationwide health survey
}

\author{
Shin Young Ahn $\mathbb{D}^{1,2}$, Yoon Jin $\mathrm{Choi}^{3}$, Jieun $\mathrm{Kim}^{2}$, Gang Jee $\mathrm{Ko}^{1,2}$, Young Joo Kwon ${ }^{1,2}$ \& \\ Kyungdo $\operatorname{Han}^{4 凶}$
}

Several studies have demonstrated the nephroprotective effects of estrogen on renal damage. In light of the inconsistent results of previous findings, this study aims to evaluate the in-depth role of menopausal hormone therapy (MHT) on the development of end stage renal disease (ESRD). $3,109,506$ Korean adult women who had undergone a medical examination in 2009 (index year) were initially identified for inclusion in this study. We excluded subjects had not experienced menopause naturally, had data missing for at least one variable, and were diagnosed with ESRD within 1 year from the index year. MHT data was obtained from self-reporting questionnaires and the primary outcome was the development of ESRD from the index year until December 31, 2018. A final total of 1,460,311 subjects were included in this study. The participants were divided into four groups according to the duration of $\mathrm{MHT}$; no history of $\mathrm{MHT}, \mathrm{MHT}<2$ years, $2 \leq \mathrm{MHT}<5$ years, $\mathrm{MHT} \geq 5$ years. During the 9 -year study period, a total of 4905 participants developed ESRD. The participants who had a history of MHT use were found to have a $30 \%$ reduced risk of developing ESRD. Results from the subgroup analyses were similar to that of the primary study. The findings in this study demonstrate the beneficial effects of MHT on the development of ESRD in postmenopausal women. Based on results, our study may offer suggestions for further studies to investigate the therapeutic options on kidney disease.

A significant factor for explaining the differences in disease incidence and prevalence is biological sex. Cardiovascular disease (CVD), considered a representative disease, highlights the important differences between morbidity and mortality risk in men and women ${ }^{1}$. Throughout previous studies, sex hormones have been shown to have an important role in the development and progression of various CVDs ${ }^{2}$. Similar sex disparities have been reported in kidney diseases including incidence, prevalence, rate of progression, and outcomes of kidney diseases. Furthermore, several factors related to sex, such as genetics, hormones, social habits, economic status, and family support affect the development, progression, burden, and outcome of renal disease ${ }^{3,4}$. Despite the global burden of chronic kidney disease (CKD), little attention has been given to sex disparities in CKD. Moreover, the results of studies that explore the implications of sex hormones on kidney diseases are still inconsistent ${ }^{5-7}$ and mainly male versus female.

The beneficial effects of estrogen on the kidney have been well explored through many clinical ${ }^{8,9}$ and experimental studies ${ }^{10,11}$. As expected, a peak in the prevalence of end stage renal disease (ESRD) was observed in perimenopausal women, when the activity of female hormones started to decline ${ }^{12}$. However, there are few studies that investigate the benefits of estrogen treatment on the development and progression of kidney disease.

Therefore, this paper further investigates the beneficial effects of menopausal hormone therapy (MHT) on the development of ESRD in postmenopausal women by significantly expanding the population size through the utilization of a nationwide population-based study. An overall improved understanding of the effects of MHT can better help nephrologists to address patient needs.

${ }^{1}$ Department of Internal Medicine, Korea University College of Medicine, Seoul, Republic of Korea. ${ }^{2}$ Department of Internal Medicine, Korea University Guro Hospital, Seoul, Republic of Korea. ${ }^{3}$ Department of Internal Medicine, Yonsei University College of Medicine, Seoul, Republic of Korea. ${ }^{4}$ Department of Statistics and Actuarial Science, Soongsil University, 369 Sangdo-ro, Dongjak-gu, Seoul 06978, Republic of Korea. ${ }^{\bowtie}$ email: hkd917@naver.com 


\begin{tabular}{|c|c|c|c|c|c|}
\hline \multirow[b]{2}{*}{ Variables } & \multirow[b]{2}{*}{\begin{tabular}{|l} 
No MHT \\
$(\mathrm{n}=\mathbf{1 , 2 2 8 , 2 0 3 )}$
\end{tabular}} & \multicolumn{3}{|l|}{ MHT } & \multirow[b]{2}{*}{$p$-value } \\
\hline & & $<2$ years $(n=134,394)$ & $\begin{array}{l}2 \leq<5 \text { years } \\
(\mathrm{n}=55,187)\end{array}$ & $\geq 5$ years $(n=42,527)$ & \\
\hline Age & $62.5 \pm 8.7$ & $58.4 \pm 6.7$ & $59.9 \pm 6.4$ & $60.8 \pm 6.0$ & $<0.0001$ \\
\hline \multicolumn{5}{|l|}{\begin{tabular}{|l|} 
Age groups \\
\end{tabular}} & $<0.0001$ \\
\hline $40 \leq$ age $<50$ & $37,597(3.1 \%)$ & $8070(6 \%)$ & $2353(4.3 \%)$ & $979(2.3 \%)$ & \\
\hline $50 \leq$ age $<60$ & $462,074(37.6 \%)$ & $69,613(51.8 \%)$ & 27,657 (50.1\%) & $15,711(36.9 \%)$ & \\
\hline Age $\geq 60$ years & $728,532(59.3 \%)$ & $56,711(42.2 \%)$ & $25,177(45.6 \%)$ & $25,837(60.8 \%)$ & \\
\hline Diabetes & $172,124(14.0 \%)$ & $13,527(10.1 \%)$ & $5157(9.3 \%)$ & $4330(10.2 \%)$ & $<0.0001$ \\
\hline Hypertension & $550,614(44.8 \%)$ & $47,804(35.6 \%)$ & $20,020(36.3 \%)$ & $16,951(39.9 \%)$ & $<0.0001$ \\
\hline Dyslipidemia & $421,498(34.3 \%)$ & $46,087(34.3 \%)$ & $17,983(32.6 \%)$ & $13,533(31.8 \%)$ & $<0.0001$ \\
\hline CKD & $154,623(12.6 \%)$ & $12,347(9.2 \%)$ & $5442(9.9 \%)$ & $5352(12.6 \%)$ & $<0.0001$ \\
\hline WC $(\mathrm{cm})$ & $80.4 \pm 8.6$ & $78.8 \pm 8.1$ & $78.2 \pm 8.5$ & $78.4 \pm 7.6$ & $<0.0001$ \\
\hline BMI $\left(\mathrm{kg} / \mathrm{m}^{2}\right)$ & $24.3 \pm 3.2$ & $23.9 \pm 2.9$ & $23.7 \pm 2.8$ & $23.8 \pm 2.8$ & $<0.0001$ \\
\hline $\begin{array}{l}\text { Obesity }(\mathrm{BMI} \geq 25 \mathrm{~kg} / \\
\left.\mathrm{m}^{2}\right)\end{array}$ & $472,861(38.5 \%)$ & $44,442(33.1 \%)$ & $16,382(29.7 \%)$ & $13,288(31.3 \%)$ & $<0.0001$ \\
\hline \multicolumn{5}{|l|}{ Smoking status } & $<0.0001$ \\
\hline Never smoker & $1,183,715(96.4 \%)$ & $128,411(95.6 \%)$ & $52,601(95.3 \%)$ & $40,538(95.3 \%)$ & \\
\hline Ex-smoker & $12,002(1.0 \%)$ & $1991(1.5 \%)$ & $894(1.6 \%)$ & $747(1.8 \%)$ & \\
\hline Current smoker & $32,486(2.7 \%)$ & $3992(3.0 \%)$ & $1692(3.1 \%)$ & $1242(2.9 \%)$ & \\
\hline \multicolumn{5}{|l|}{ Alcohol consumption } & $<0.0001$ \\
\hline No. & $1,087,587(88.6 \%)$ & $112,517(83.7 \%)$ & $45,919(83.2 \%)$ & $35,886(84.4 \%)$ & \\
\hline Mild drink & $134,837(11.0 \%)$ & $20,977(15.6 \%)$ & $8890(16.1 \%)$ & $6359(15.0 \%)$ & \\
\hline Heavy drink & $5779(0.5 \%)$ & $900(0.7 \%)$ & $378(0.7 \%)$ & $282(0.7 \%)$ & \\
\hline Physical activity & $210,843(17.2 \%)$ & $30,161(22.5 \%)$ & $13,487(24.4 \%)$ & $11,190(26.3 \%)$ & $<0.0001$ \\
\hline
\end{tabular}

Table 1. Baseline characteristics of the study populations according to history of MHT. BMI body mass index, $C K D$ chronic kidney disease, $M H T$ menopausal hormone therapy, $W C$ waist circumference. $\mathrm{P}<0.05$ indicates a significant difference among groups by ANOVA.

\section{Results}

Baseline characteristics of study population. The study population was assigned to four groups according to the duration of MHT; no history of MHT, MHT < 2 years, $2 \leq \mathrm{MHT}<5$ years, MHT $\geq 5$ years. $84.1 \%$ $(\mathrm{n}=1,228,203$ participants) of the study population had not received MHT compared with $15.9 \%(\mathrm{n}=232,108$ participants) who had. The baseline characteristics of the cohort are shown in Table 1. The subjects with no history of MHT were more likely to be older and have diabetes, hypertension, dyslipidemia, CKD, and obesity. As expected, they were less likely to smoke, drink alcohol, or exercise.

The reproductive histories of the four groups of women are shown in Table 2. The participants who had never received MHT were more likely to have more than two offspring, a longer duration of breast feeding ( $\geq 12$ months), and to have started menstruation at an older age. Additional findings showed that they were less likely to take oral contraceptives and that the percentage experiencing menopause before the age of fifty was low.

MHT and the risk of ESRD. During the 9-year study period, a total of 4,905 participants developed ESRD. The Kaplan-Meier curves showed a significant overall reduction in the incidence of ESRD in subjects who had received MHT regardless of duration (Fig. 1). After adjusting for possible confounding factors such as age, BMI, smoking history, alcohol intake, physical activities, hypertension, diabetes, dyslipidemia, and CKD, the participants who had a history of MHT use had a significantly lower risk of developing ESRD (MHT $<2$ years, HR $0.634,95 \%$ CI $0.556-0.723 ; 2 \leq \mathrm{MHT}<5$ years, HR $0.721,95 \%$ CI $0.597-0.871 ;$ MHT $\geq 5$ years, HR $0.654,95 \%$ CI 0.531-0.806) (Table 3).

Our research also showed that the early menopausal group (age at a menopause $<50$ years) had an increased risk for the incidence of ESRD (HR 1.079, 95\% CI 1.016-1.146) compared to the reference group (50 $\leq$ age at menopause $<55$ years) (Table S1).

Subgroup analysis. Stratified analysis according to age, diabetes, hypertension, obesity and CKD revealed further patterns in the data (Table 4). Subjects receiving MHT consistently showed a reduced risk of ESRD development compared to subjects without MHT. In particular, the beneficial effects of MHT were clearly observed in participants who were younger ( $<65$ years), had diabetes and hypertension. These favorable effects of MHT continued regardless of obesity and CKD status (Table 4 ). 


\begin{tabular}{|c|c|c|c|c|c|}
\hline \multirow[b]{2}{*}{ Variables } & \multirow[b]{2}{*}{$\begin{array}{l}\text { No MHT } \\
(n=1,228,203)\end{array}$} & \multicolumn{3}{|l|}{ MHT } & \multirow[b]{2}{*}{$p$-value } \\
\hline & & $<2$ years $(n=134,394)$ & $\begin{array}{l}2 \leq<5 \text { years } \\
(\mathrm{n}=55,187)\end{array}$ & $\geq 5$ years $(n=42,527)$ & \\
\hline \multicolumn{5}{|l|}{ Parity } & $<0.0001$ \\
\hline 1 person & $66,774(5.4 \%)$ & $10,996(8.2 \%)$ & $4788(8.7 \%)$ & $3461(8.1 \%)$ & \\
\hline$\geq 2$ persons & $1,135,472(92.5 \%)$ & $118,525(88.2 \%)$ & $48,320(87.6 \%)$ & $37,254(87.6 \%)$ & \\
\hline No & $25,957(2.1 \%)$ & $11,957(2.9 \%)$ & $4973(3.2 \%)$ & $4407(3.5 \%)$ & \\
\hline \multicolumn{5}{|l|}{ Breast feeding } & $<0.0001$ \\
\hline$<6$ months & $71,822(5.9 \%)$ & $11,527(8.6 \%)$ & $4822(8.7 \%)$ & $3338(7.9 \%)$ & \\
\hline $6 \leq<12$ months & $200,851(16.4 \%)$ & $27,349(20.4 \%)$ & $11,459(20.8 \%)$ & $7548(17.8 \%)$ & \\
\hline$\geq 12$ months & $883,625(71.9 \%)$ & $83,960(62.5 \%)$ & $33,630(60.9 \%)$ & $27,583(64.9 \%)$ & \\
\hline Not done & $71,905(5.9 \%)$ & $11,558(8.6 \%)$ & $5276(9.6 \%)$ & $4058(9.5 \%)$ & \\
\hline \multicolumn{5}{|l|}{ Oral contraceptives } & $<0.0001$ \\
\hline No & $1,023,263(83.3 \%)$ & 96,284 (71.6\%) & $39,055(70.8 \%)$ & $29,619(69.7 \%)$ & \\
\hline Yes & $164,257(13.4 \%)$ & $32,866(24.5 \%)$ & $13,450(24.4 \%)$ & $10,560(24.8 \%)$ & \\
\hline Unknown & $40,683(3.3 \%)$ & $5,244(3.9 \%)$ & $2,682(4.9 \%)$ & $2,348(5.5 \%)$ & \\
\hline Age at menarche & $16.5 \pm 1.8$ & $16.2 \pm 1.8$ & $16.2 \pm 1.8$ & $16.3 \pm 1.8$ & $<0.0001$ \\
\hline Menarche $<11$ years & $893(0.1 \%)$ & $126(0.1 \%)$ & $45(0.1 \%)$ & $31(0.1 \%)$ & 0.0573 \\
\hline Age at menopause & $50.0 \pm 4.0$ & $50.0 \pm 4.0$ & $50.0 \pm 4.2$ & $49.4 \pm 4.8$ & $<0.0001$ \\
\hline \multicolumn{5}{|c|}{ Groups of menopause ages } & $<0.0001$ \\
\hline$<50$ years & $418,092(34.0 \%)$ & $50,630(37.7 \%)$ & $21,590(39.1 \%)$ & $18,828(44.3 \%)$ & \\
\hline $50 \leq$ age $<55$ years & $679,630(55.3 \%)$ & 69,609 (51.8\%) & $27,173(49.3 \%)$ & $18,658(43.9 \%)$ & \\
\hline$\geq 55$ years & $130,481(10.6 \%)$ & $14,155(10.5 \%)$ & 6,424(11.6\%) & $5,041(11.9 \%)$ & \\
\hline Follow up period (years) & $9.2 \pm 1.3$ & $9.3 \pm 0.8$ & $9.3 \pm 0.8$ & $9.3 \pm 0.8$ & $<0.0001$ \\
\hline
\end{tabular}

Table 2. Reproductive parameters of the study population according to history of MHT. MHT menopausal hormone therapy. $\mathrm{P}<0.05$ indicates a significant difference among groups by ANOVA.

\section{ESRD}

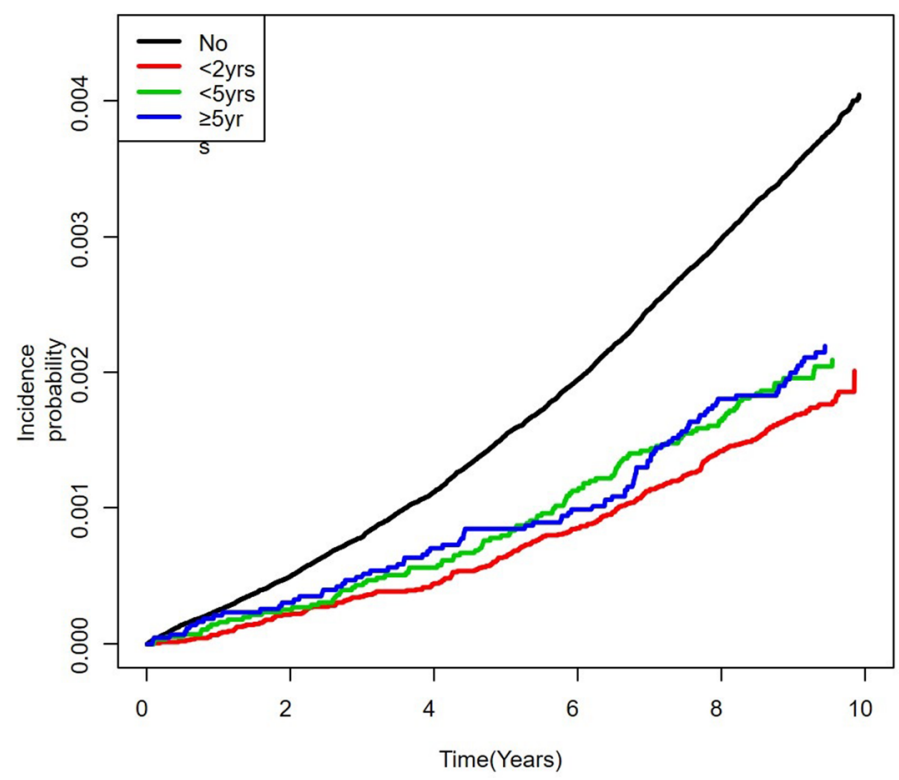

Figure 1. The Kaplan-Meier curves for development of ESRD according to the duration of MHT.

\section{Discussion}

This nationwide population-based study showed the beneficial effects of MHT on the development of ESRD in postmenopausal women during the 9-year study period. MHT significantly reduced the risk of developing ESRD regardless of duration. These favorable MHT effects confirmed even after adjusting for potential confounders including age, BMI, lifestyle, and comorbidities. In addition, stratified analyses were performed in subgroups based on age, diabetes, hypertension, obesity, and CKD status. As with the original findings in this study, MHT 


\begin{tabular}{|l|r|r|l|l|l|}
\hline Total population & No. & Outcome & IR & Model 1 $^{\text {a }}$ & Model 2 $^{\mathbf{b}}$ \\
\hline MHT & \multicolumn{7}{|l|}{} \\
\hline No MHT & $1,228,203$ & 4468 & 0.397 & 1 (ref.) & 1 (ref.) \\
\hline MHT $<2$ years & 134,394 & 236 & 0.188 & $0.474(0.415,0.540)$ & $0.634(0.556,0.723)$ \\
\hline $2 \leq$ MHT $<5$ years & 55,187 & 111 & 0.216 & $0.543(0.450,0.655)$ & $0.721(0.597,0.871)$ \\
\hline MHT $\geq 5$ years & 42,527 & 90 & 0.227 & $0.571(0.463,0.703)$ & $0.654(0.531,0.806)$ \\
\hline
\end{tabular}

Table 3. Hazard ratios and $95 \%$ confidence intervals of ESRD development by history of MHT. ESRD end stage renal disease, $M H T$ menopausal hormone therapy. ${ }^{a}$ Model 1: Not adjusted. ${ }^{b}$ Model 2: Cox proportional model adjusted for age, BMI, smoking history, drinking history, degree of exercise, hypertension, dyslipidemia, diabetes, and CKD.

was also shown to have reduced the risk of incident ESRD in almost all stratified subgroups. Finally, we observed that the age for menopause might affect the risk of ESRD development. As expected, the younger onset of menopause showed a higher risk of ESRD incidence even after multivariate adjustments. These results may be evidence that a female hormone, represented by estrogen, may help slow the progression of ESRD.

In previous studies, we found clear and consistent sex disparities in the clinical course and outcomes of patient with $\mathrm{CKD}^{13-16}$. Clinical and experimental research has demonstrated the protective effect of estrogen on renal outcome. The findings showed that estrogen provides a protective effect on the physiologic and pathologic processes of the kidney via the three estrogen receptors located in the renal tissues ${ }^{17-19}$. The animal models showed that the antifibrotic and anti-apoptotic effects of estrogen retard the rate of CKD progression in diabetic ${ }^{20}$ and nondiabetic nephropathy. Specifically, models included aging ${ }^{21}$, polycystic disease ${ }^{22}$, ischemic-reperfusion injury $^{23}$, and adenine treatment ${ }^{24}$. Through histologic evidences of those experimental models, we demonstrated that estrogen reduced mesangial expansion, attenuated the glomerular hypertrophy as well as podocyte loss, and decreased interstitial fibrosis and collagen deposition. In contrast, male sex hormones are known to have deleterious effects that contribute to inflammatory process in the physiologic and pathologic conditions. In diabetic castrated male rats, several hallmarks of kidney damages such as, albuminuria, glomerulosclerosis, and tubulointerstitial fibrosis worsened in proportion to the dose of dihydrotestosterone ${ }^{25}$. Testosterone supplementation also induced podocyte apoptosis in ovariectomized wild-type mice ${ }^{26}$. In various other disease models, testosterone had a negative effect on kidney damage $\mathrm{e}^{24,27}$. Based on these findings, it can be deduced that estrogen provides a renoprotective effect for women. However, despite numerous published studies on the link between sex hormones and CKD, the effects are still controversial.

In general, population based studies reveal that the prevalence of CKD among women is higher than in men. Additionally, epidemiologic studies further support this finding ${ }^{13}$. There are several explanations for these results. First, women have longer life expectancy, as a result, aging process can cause decline of kidney function naturally. Second, the equations for estimating GFR, such as MDRD or Chronic Kidney Disease Epidemiology Collaboration (CKD-EPI) have several measurements bias. These then lead to underestimated eGFR calculations by these equations in women ${ }^{28,29}$. Therefore, sex-specific thresholds of eGFR are required to determine an accurate prevalence measurement of $\mathrm{CKD}^{30}$.

Although, the overall prevalence of CKD is higher in women and the CKD progression differences disappear in postmenopausal women, the rate of CKD progression is lower in premenopausal women than in men of the same age ${ }^{31}$. This phenomenon has been explained by the results of the aforementioned studies. Moreover, most population-based studies demonstrate that men have a steeper slope of the rate of eGFR decline than women $^{32}$. The rate of eGFR decline has been attributed to the contrary effects of sex hormones, comparatively higher prevalence of unhealthy lifestyles in men, and the inherent protective effects of estrogen ${ }^{33-35}$. In addition to these differences, we also observed the beneficial effects of estrogen therapy on the development of ESRD in postmenopausal women. In connection to this observation, we showed that women who experience an earlier onset of menopause, meaning a shorter period of estrogen production, yielded a faster progression of ESRD. Our results are consistent with the results of previous studies showing the protective role of estrogen in the development and progression of CKD.

There are limitations to our study. First, the data regarding reproductive history were collected by selfreporting questionnaires (Supplementary Material). Therefore, there was also inevitably a recall bias and we could not obtain detailed information about MHT; drug formulation, routes of administration, compliance over the duration of MHT, and reasons for stopping MHT. However, menopausal women who did not experience menopause naturally because of hysterectomy or bilateral oophorectomy were excluded from the analysis in this study. Considering that the physicians prescribed an estrogen-progestogen combination drug to women with the uterus because of the risk of endometrial cancer, the MHT drug used in this study is more likely to be a combination drug. According to an analysis of the domestic consumption of postmenopausal hormonal medicine in the year 2010 reported by Cho et al., combination drug was the highest at 53\%, followed by Tibolone at $40 \%$ and estrogen alone at $7 \%{ }^{36}$. Second, this was a population-based observational study. Therefore, there might be confounders that we did not consider. Third, the participants who received hormone therapy were more likely to have an interest in their health and well-being and they have a healthier lifestyle which contributes to slow development and progression of CKD. Fourth, the study population consisted of Korean postmenopausal women and so far that reason, the results of this study could not be generalized to other ethnicities. However, we can find other population studies that are based on various ethnicities and demonstrated the protective effect of estrogen on renal outcome. Fifth, the causes of ESRD were not identified in our study. 


\begin{tabular}{|c|c|c|c|c|}
\hline Subgroups & No. & Outcome & IR & HR $(95 \% \mathrm{CI})^{*}$ \\
\hline \multicolumn{5}{|l|}{ Age $<65$ years } \\
\hline No MHT & 744,473 & 1900 & 0.274 & 1 (ref.) \\
\hline MHT < 2 years & 110,403 & 155 & 0.150 & $0.633(0.538,0.746)$ \\
\hline $2 \leq \mathrm{MHT}<5$ years & 45,591 & 75 & 0.176 & $0.735(0.583,0.926)$ \\
\hline MHT $\geq 5$ years & 32,121 & 52 & 0.173 & $0.639(0.485,0.843)$ \\
\hline \multicolumn{5}{|l|}{ Age $\geq 65$ years } \\
\hline No MHT & 483,730 & 2568 & 0.594 & 1 (ref.) \\
\hline MHT $<2$ years & 23,991 & 81 & 0.367 & $0.660(0.528,0.824)$ \\
\hline $2 \leq \mathrm{MHT}<5$ years & 9596 & 36 & 0.408 & $0.740(0.532,1.029)$ \\
\hline MHT $\geq 5$ years & 10,406 & 38 & 0.395 & $0.710(0.515,0.979)$ \\
\hline \multicolumn{5}{|l|}{ Diabetes (-) } \\
\hline No MHT & $1,056,079$ & 2231 & 0.229 & 1 (ref.) \\
\hline MHT < 2 years & 120,867 & 140 & 0.124 & $0.693(0.584,0.824)$ \\
\hline $2 \leq \mathrm{MHT}<5$ years & 50,030 & 75 & 0.161 & $0.858(0.680,1.081)$ \\
\hline MHT $\geq 5$ years & 38,197 & 53 & 0.149 & $0.664(0.505,0.872)$ \\
\hline \multicolumn{5}{|l|}{ Diabetes (+) } \\
\hline No MHT & 172,124 & 2237 & 1.455 & 1 (ref.) \\
\hline MHT < 2 years & 13,527 & 96 & 0.769 & $0.578(0.471,0.710)$ \\
\hline $2 \leq \mathrm{MHT}<5$ years & 5157 & 36 & 0.760 & $0.560(0.403,0.779)$ \\
\hline MHT $\geq 5$ years & 4330 & 37 & 0.926 & $0.647(0.467,0.895)$ \\
\hline \multicolumn{5}{|l|}{ Hypertension (-) } \\
\hline No MHT & 677,589 & 796 & 0.127 & 1 (ref.) \\
\hline MHT < 2 years & 86,590 & 45 & 0.056 & $0.555(0.410,0.752)$ \\
\hline $2 \leq \mathrm{MHT}<5$ years & 35,167 & 29 & 0.088 & $0.860(0.593,1.248)$ \\
\hline MHT $\geq 5$ years & 25,576 & 17 & 0.071 & $0.611(0.378,0.988)$ \\
\hline \multicolumn{5}{|l|}{ Hypertension (+) } \\
\hline No MHT & 550,614 & 3672 & 0.735 & 1 (ref.) \\
\hline MHT < 2 years & 47,804 & 191 & 0.430 & $0.662(0.572,0.767)$ \\
\hline $2 \leq \mathrm{MHT}<5$ years & 20,020 & 82 & 0.441 & $0.686(0.550,0.854)$ \\
\hline MHT $\geq 5$ years & 16,951 & 73 & 0.464 & $0.660(0.523,0.833)$ \\
\hline \multicolumn{5}{|l|}{$\mathrm{BMI}<25 \mathrm{~kg} / \mathrm{m}^{2}$} \\
\hline No MHT & 755,342 & 2478 & 0.359 & 1 (ref.) \\
\hline MHT < 2 years & 89,952 & 143 & 0.170 & $0.644(0.543,0.763)$ \\
\hline $2 \leq \mathrm{MHT}<5$ years & 38,805 & 73 & 0.202 & $0.746(0.591,0.943)$ \\
\hline MHT $\geq 5$ years & 29,239 & 59 & 0.216 & $0.670(0.517,0.868)$ \\
\hline \multicolumn{5}{|l|}{$\mathrm{BMI} \geq 25 \mathrm{~kg} / \mathrm{m}^{2}$} \\
\hline No MHT & 472,861 & 1990 & 0.457 & 1 (ref.) \\
\hline MHT < 2 years & 44,442 & 93 & 0.224 & $0.631(0.512,0.777)$ \\
\hline $2 \leq \mathrm{MHT}<5$ years & 16,382 & 38 & 0.249 & $0.695(0.504,0.958)$ \\
\hline MHT $\geq 5$ years & 13,288 & 31 & 0.250 & $0.651(0.456,0.929)$ \\
\hline \multicolumn{5}{|l|}{ CKD (-) } \\
\hline No MHT & $1,073,580$ & 1523 & 0.15384 & 1 (ref.) \\
\hline MHT < 2 years & 122,047 & 92 & 0.08073 & $0.675(0.546,0.835)$ \\
\hline $2 \leq \mathrm{MHT}<5$ years & 49,745 & 38 & 0.08182 & $0.698(0.506,0.965)$ \\
\hline MHT $\geq 5$ years & 37,175 & 30 & 0.08642 & $0.679(0.473,0.975)$ \\
\hline \multicolumn{5}{|l|}{ CKD (+) } \\
\hline No MHT & 154,623 & 2945 & 2.161 & 1 (ref.) \\
\hline MHT $<2$ years & 12,347 & 144 & 1.268 & $0.610(0.515,0.721)$ \\
\hline $2 \leq \mathrm{MHT}<5$ years & 5442 & 73 & 1.461 & $0.725(0.574,0.915)$ \\
\hline MHT $\geq 5$ years & 5352 & 60 & 1.218 & $0.622(0.482,0.804)$ \\
\hline
\end{tabular}

Table 4. Hazard ratios and 95\% confidence intervals of ESRD development by history of MHT in subgroups. ESRD end stage renal disease, $M H T$ menopausal hormone therapy, $B M I$, body mass index, $C K D$, chronic kidney disease. ${ }^{\star} H R$ Cox proportional model adjusted for age, BMI, smoking history, drinking history, degree of exercise, hypertension, dyslipidemia, diabetes, and CKD. 


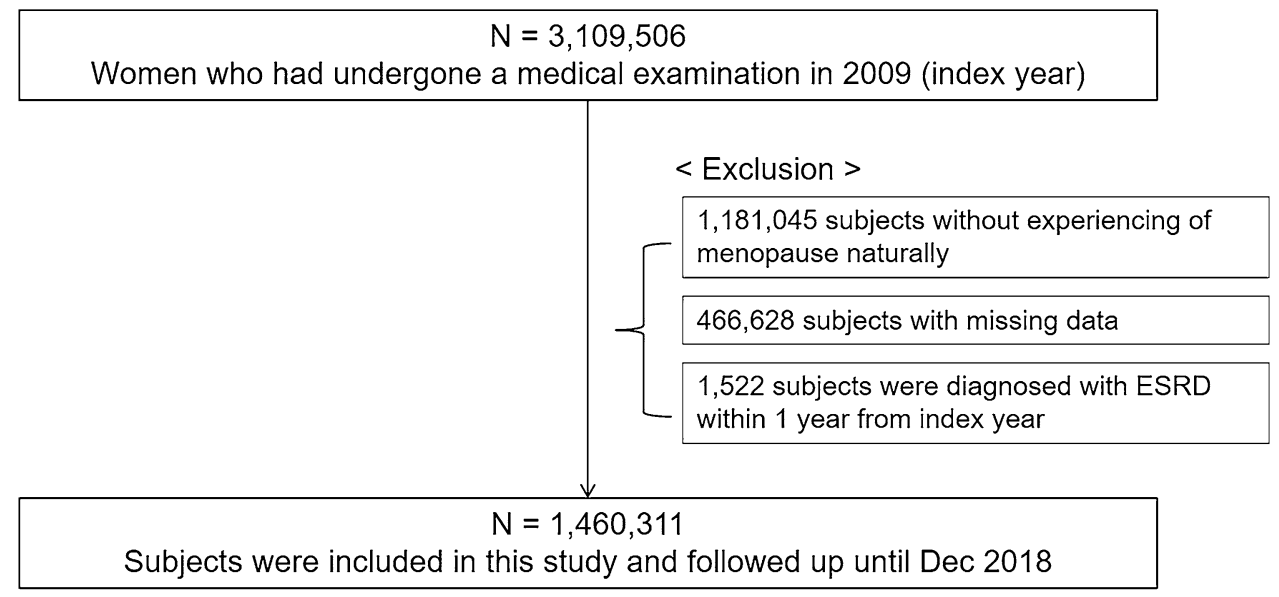

Figure 2. The schematic flow chart of the study population.

Despite the limitations mentioned above, our study is the largest population-based study to demonstrate the favorable effects of MHT on the development of ESRD in postmenopausal women. This study analyzed a 9-year period of data contained in the Korean NHID that includes medical information for 50 million Koreans making it sufficient to overcome several unmeasured biases.

Our study showed the presence of beneficial effects of MHT on the development of ESRD in postmenopausal women during the 9-year study period. MHT, regardless of duration, significantly reduced the risk of developing ESRD. These favorable effects were confirmed even after conducting subgroup analyses. In existing literature, there is a still controversy for the effect of sex hormones on the development and progression of kidney disease. However, this study finds that female hormones based on estrogen provides a protective effect against ESRD. Therefore, our study may offer suggestions for further studies to investigate the therapeutic effects of estrogen on kidney disease.

\section{Methods}

Data source and study population. The National Health Insurance Service (NHIS) of Korea provided access to the National Health Insurance Database (NHID) that contains data on eligibility, medical treatment, health examination, and medical care institution ${ }^{37,38}$. The NHID contains the health information of approximately 50 million Koreans who are enrolled in a single-payer healthcare system and are required to have biannual standardized medical examinations.

$3,109,506$ Korean adult women who had undergone a medical examination in 2009 (index year) were initially identified for inclusion in this study. We excluded subjects who were diagnosed as not having menopause naturally $(\mathrm{n}=1,181,045)$, had missing data for at least one variable $(\mathrm{n}=466,628)$, and were diagnosed with ESRD within 1 year from the index year $(n=1,522)$ (Fig. 2). As a consequence, $1,460,311$ subjects were included in this study and tracked from the index year to December 31, 2018.

Ethics declarations. This study was approved by the Institutional Review Board of the Korea University Guro Hospital. (IRB No. 2019GR0222). This study was also approved by National Health Insurance Service (NHIS-2020-1-307). The informed consent was waived for all subjects by the Committee of Institutional Review Board of the Korea University Guro Hospital.

Demographic and lifestyle variables. Demographic characteristics including age, gender, amount of alcohol consumption, smoking status, and physical activity were collected using self-reported questionnaires. Medical examination data included height, weight, waist circumference, blood pressure, laboratory tests, past medical history, and health related behaviors. Definitions of demographic and lifestyle variables are described in accordance to previous studies ${ }^{39,40}$. Participants were categorized into 3 groups based on drinking frequency: non-drinker, $\leq 1$ drink per month; light drinker, $>1$ drink but $<2$ drinks per week; heavy drinker, $>2$ drinks per week. The study population was also assigned to one of 3 groups according to the participant's smoking status: non-smoker, ex-smoker, and smoker. A "yes" response for the physical activity query required the participant to be active beyond the normal activities of daily living, that the duration exceeds $30 \mathrm{~min}$, and have a frequency of more than five times per week.

Variables for reproduction. The questionnaires yielded data for the variables for reproduction (Supplementary Material): age at menarche, age at menopause, parity number, history of oral contraceptives, history of MHT, and history of breast feeding. Menopause was defined as the absence of menstruations for 12 consecutive months in the absence of procedures that stopped menstruation including hysterectomy and oophorectomy. Study populations were categorized into 4 groups differentiated based on the duration of MHT; no MHT, 
MHT $<2$ years, $2 \leq$ MHT $<5$ years, and MHT $\geq 5$ years. Parity was defined in terms live births and divided into 3 groups; no live birth, one live birth, and more than two live births. Participants were also categorized into 4 groups according to the duration of breast feeding; no breast feeding, breast feeding $<6$ months, $6 \leq$ breast feeding $<12$ months, and breast feeding $\geq 12$ months. We also divided the study populations into several subgroups depending on age at menarche (age $<11$ years and age $\geq 11$ years) and age at menopause (age $<50$ years, $50 \leq$ age $<55$ years, and age $\geq 55$ years).

Comorbidities. The detailed definitions of comorbidities are described in previous studies ${ }^{41}$. Patients with hypertension included those who submitted either at least one claim in a year for a prescription of anti-hypertensive medication or measured systolic/diastolic blood pressure $\geq 140 / 90 \mathrm{mmHg}$. Diabetes included those who submitted at least one claim in a year for a prescription of anti-diabetic medication or fasting plasma glucose level $\geq 126 \mathrm{mg} / \mathrm{dL}$. Lastly, dyslipidemia included those who submitted either at least one claim in a year for a prescription of anti-dyslipidemic medication or exhibited a total serum cholesterol level $\geq 240 \mathrm{mg} / \mathrm{dL}$. Glomerular filtration rate (GFR) was calculated using the four variable isotope dilution mass spectrometry (IDMS) Modification of Diet in Renal Disease (MDRD) formula: $175 \times$ serum Cr $(\mathrm{mg} / \mathrm{dL})^{-1.154} \times$ age (year) ${ }^{-0.203} \times 0.742$ (if female) $^{42}$ and CKD was defined as an eGFR $<60 \mathrm{~mL} / \mathrm{min} / 1.73 \mathrm{~m}^{243}$. Body-mass index (BMI) and waist circumference data were measured by a trained examiner. Obesity was defined as a BMI of more than $25 \mathrm{~kg} / \mathrm{m}^{2}$ according to the Korean Endocrine Society ${ }^{44}$. According to the World Health Organization (WHO), the cutoff value for defining obesity is lower for East Asians than for non-Asians.

Primary outcome. The primary outcome was incident ESRD until December 31, 2018. ESRD was defined using the combination of a $\mathrm{V}$ code assigned to patients who required hemodialysis (V001), peritoneal dialysis (V003), or kidney transplantation (V005) and an ICD-10 code (N18-19, Z49, Z94.0, Z99.2), as previously defined in other studies ${ }^{41}$. All medical costs for dialysis were reimbursed and ESRD patients were registered as special medical aid beneficiaries. This enabled the location of all ESRD patients in the Korean population, especially data on those who had started dialysis. However, we excluded participants with no previous chronic kidney disease who had a kidney transplantation or dialysis code on the same date as an acute renal failure code. Subjects receiving continuous renal replacement therapy or acute peritoneal dialysis were also excluded.

Statistical analysis. Data are presented as the mean \pm standard deviation for continuous variables and the numbers and percentages for categorical variables. The baseline demographic, lifestyle, and reproductive variables were compared according to subgroups based on history and duration of MHT using ANOVA test for continuous variables and chi-squared test for categorical variables. The cumulative incidence of ESRD according to the duration of MHT was evaluated using the Kaplan-Meier curves, and log-rank test was used to analyze differences between groups. The multivariable-adjusted proportional-hazards model was applied. It was adjusted for age, BMI, smoking status, categories of drinking frequency, physical activity, HTN, DM, dyslipidemia, and CKD. The hazard ratios (HRs) and 95\% confidence intervals (CIs) for ESRD according to the subgroups categorized by demographic and clinical factors were evaluated using the Cox proportional-hazards model. A p-value of less than 0.05 was considered statistically significant.

Received: 15 August 2020; Accepted: 5 April 2021

Published online: 29 July 2021

\section{References}

1. Mosca, L., Barrett-Connor, E. \& Wenger, N. K. Sex/gender differences in cardiovascular disease prevention: What a difference a decade makes. Circulation 124(19), 2145-2154 (2011).

2. Guajardo, I. et al. Sex differences in vascular dysfunction and cardiovascular outcomes: The cardiac, endothelial function, and arterial stiffness in ESRD (CERES) study. Hemodial Int. 22(1), 93-102 (2018).

3. Carrero, J. J. Gender differences in chronic kidney disease: Underpinnings and therapeutic implications. Kidney Blood Press. Res. 33(5), 383-392 (2010).

4. Cobo, G. et al. Sex and gender differences in chronic kidney disease: Progression to end-stage renal disease and haemodialysis. Clin. Sci. (Lond.) 130(14), 1147-1163 (2016).

5. Monster, T. B. et al. Oral contraceptive use and hormone replacement therapy are associated with microalbuminuria. Arch. Intern. Med. 161(16), 2000-2005 (2001).

6. Ahmed, S. B. et al. Oral estrogen therapy in postmenopausal women is associated with loss of kidney function. Kidney Int. 74(3), 370-376 (2008).

7. Khurana, K. K. et al. Serum testosterone levels and mortality in men with CKD stages 3-4. Am. J. Kidney Dis. 64(3), 367-374 (2014).

8. Kattah, A. G. et al. CKD in Patients with bilateral oophorectomy. Clin. J. Am. Soc. Nephrol. 13(11), 1649-1658 (2018).

9. Melamed, M. L. et al. Raloxifene, a selective estrogen receptor modulator, is renoprotective: A post-hoc analysis. Kidney Int. 79(2), 241-249 (2011).

10. Mercantepe, T. et al. Protective effects of estrogen and bortezomib in kidney tissue of post-menopausal rats: An ultrastructural study. Ren. Fail. 38(7), 1129-1135 (2016).

11. Abd El-Lateef, S. M., El-Sayed, E. M., Mansour, A. M. \& Salama, S. A. The protective role of estrogen and its receptors in gentamicin-induced acute kidney injury in rats. Life Sci. 239, 117082 (2019).

12. Kummer, S., von Gersdorff, G., Kemper, M. J. \& Oh, J. The influence of gender and sexual hormones on incidence and outcome of chronic kidney disease. Pediatr. Nephrol. 27(8), 1213-1219 (2012).

13. Carrero, J. J., Hecking, M., Chesnaye, N. C. \& Jager, K. J. Sex and gender disparities in the epidemiology and outcomes of chronic kidney disease. Nat. Rev. Nephrol. 14(3), 151-164 (2018). 
14. Valdivielso, J. M., Jacobs-Cacha, C. \& Soler, M. J. Sex hormones and their influence on chronic kidney disease. Curr. Opin. Nephrol. Hypertens. 28(1), 1-9 (2019).

15. Brar, A. \& Markell, M. Impact of gender and gender disparities in patients with kidney disease. Curr. Opin. Nephrol. Hypertens. 28(2), 178-182 (2019).

16. Neugarten, J. \& Golestaneh, L. Influence of sex on the progression of chronic kidney disease. Mayo Clin. Proc. 94(7), 1339-1356 (2019).

17. Lubahn, D. B. et al. Alteration of reproductive function but not prenatal sexual development after insertional disruption of the mouse estrogen receptor gene. Proc. Natl. Acad. Sci. U.S.A. 90(23), 11162-11166 (1993).

18. Krege, J. H. et al. Generation and reproductive phenotypes of mice lacking estrogen receptor beta. Proc. Natl. Acad. Sci. U.S.A. 95(26), 15677-15682 (1998).

19. Meyer, M. R., Prossnitz, E. R. \& Barton, M. The G protein-coupled estrogen receptor GPER/GPR30 as a regulator of cardiovascular function. Vasc. Pharmacol. 55(1-3), 17-25 (2011).

20. Clotet-Freixas, S. et al. Sex dimorphism in ANGII-mediated crosstalk between ACE2 and ACE in diabetic nephropathy. Lab. Investig. 98(9), 1237-1249 (2018).

21. Hajdu, A. \& Rona, G. The protective effect of estrogens against spontaneous pancratic islet and renal changes in aging male rats. Experientia 27(8), 956-957 (1971).

22. Stringer, K. D. et al. Gender hormones and the progression of experimental polycystic kidney disease. Kidney Int. 68(4), 1729-1739 (2005).

23. Hutchens, M. P., Fujiyoshi, T., Komers, R., Herson, P. S. \& Anderson, S. Estrogen protects renal endothelial barrier function from ischemia-reperfusion in vitro and in vivo. Am. J. Physiol. Renal Physiol. 303(3), F377-F385 (2012).

24. Diwan, V., Small, D., Kauter, K., Gobe, G. C. \& Brown, L. Gender differences in adenine-induced chronic kidney disease and cardiovascular complications in rats. Am. J. Physiol. Renal Physiol. 307(11), F1169-F1178 (2014).

25. Xu, Q., Prabhu, A., Xu, S., Manigrasso, M. B. \& Maric, C. Dose-dependent effects of dihydrotestosterone in the streptozotocininduced diabetic rat kidney. Am. J. Physiol. Renal Physiol. 297(2), F307-F315 (2009).

26. Doublier, S. et al. Testosterone and 17 beta-estradiol have opposite effects on podocyte apoptosis that precedes glomerulosclerosis in female estrogen receptor knockout mice. Kidney Int. 79(4), 404-413 (2011).

27. Metcalfe, P. D. et al. Testosterone exacerbates obstructive renal injury by stimulating TNF-alpha production and increasing proapoptotic and profibrotic signaling. Am. J. Physiol. Endocrinol. Metab. 294(2), E435-E443 (2008).

28. Glassock, R. J., Warnock, D. G. \& Delanaye, P. The global burden of chronic kidney disease: Estimates, variability and pitfalls. Nat. Rev. Nephrol. 13(2), 104-114 (2017).

29. Inker, L. A. et al. Performance of glomerular filtration rate estimating equations in a community-based sample of Blacks and Whites: The multiethnic study of atherosclerosis. Nephrol. Dial. Transplant. 33(3), 417-425 (2018).

30. Wetzels, J. F., Kiemeney, L. A., Swinkels, D. W., Willems, H. L. \& den Heijer, M. Age- and gender-specific reference values of estimated GFR in Caucasians: The Nijmegen Biomedical Study. Kidney Int. 72(5), 632-637 (2007).

31. Neugarten, J., Acharya, A. \& Silbiger, S. R. Effect of gender on the progression of nondiabetic renal disease: A meta-analysis. J. Am. Soc. Nephrol. 11(2), 319-329 (2000).

32. Halbesma, N. et al. Gender differences in predictors of the decline of renal function in the general population. Kidney Int. 74(4), 505-512 (2008).

33. Crews, D. C. et al. Dietary habits, poverty, and chronic kidney disease in an urban population. J. Renal Nutr. 25(2), 103-110 (2015).

34. Ellam, T., Fotheringham, J. \& Kawar, B. Differential scaling of glomerular filtration rate and ingested metabolic burden: Implications for gender differences in chronic kidney disease outcomes. Nephrol. Dial. Transplant. 29(6), 1186-1194 (2014).

35. dos Santos, R. L., da Silva, F. B., Ribeiro, R. F. Jr. \& Stefanon, I. Sex hormones in the cardiovascular system. Horm. Mol. Biol. Clin. Investig. 18(2), 89-103 (2014).

36. Cho, M. K. \& Park, H. M. The national use of hormonal therapy in postmenopausal women in 2010. J. Korean Soc. Menopause 17, $150-154$ (2011).

37. Lee, Y. H. et al. Data analytic process of a nationwide population-based study using national health information database established by National Health Insurance Service. Diabetes Metab. J. 40(1), 79-82 (2016).

38. Seong, S. C. et al. Cohort profile: The National health insurance service-national health screening cohort (NHIS-HEALS) in Korea. BMJ Open 7(9), e016640 (2017).

39. Han, K., Kim, I., Park, Y. G. \& Park, J. B. Associations between the number of natural teeth and the maternal age at childbirth or history of parity in postmenopausal women: The 2010-2012 Korea national health and nutrition examination survey. Adv. Clin. Exp. Med. 26(4), 627-633 (2017).

40. Jang, H. D. et al. Relationship between bone mineral density and alcohol intake: A nationwide health survey analysis of postmenopausal women. PLoS ONE 12(6), e0180132 (2017).

41. Kim, M. K. et al. Effects of variability in blood pressure, glucose, and cholesterol concentrations, and body mass index on end-stage renal disease in the general population of Korea. J. Clin. Med. 8(5), 755 (2019).

42. Lamb, E. J., Tomson, C. R., Roderick, P. J. \& Clinical Sciences Reviews Committee of the Association for Clinical B. Estimating kidney function in adults using formulae. Ann. Clin. Biochem. 42(Pt 5), 321-345 (2005).

43. National, K. F. K/DOQI clinical practice guidelines for chronic kidney disease: Evaluation, classification, and stratification. Am. J. Kidney Dis. 39(2 Suppl 1), S1-S266 (2002).

44. Oh, S. W., Shin, S. A., Yun, Y. H., Yoo, T. \& Huh, B. Y. Cut-off point of BMI and obesity-related comorbidities and mortality in middle-aged Koreans. Obes. Res. 12(12), 2031-2040 (2004).

\section{Author contributions}

S.Y.A. and K.H. have full access to all of the data in the study and take responsibility for the integrity of the data and the accuracy of the data analysis. S.Y.A., Y.J.C., J.K. and G.J.K. participated in research design. K.H., G.J.K. and Y.J.K. participated in analysis and interpretation of data. Y.J.C. and K.H. participated in data collection.

\section{Competing interests}

The authors declare no competing interests.

\section{Additional information}

Supplementary Information The online version contains supplementary material available at https://doi.org/ 10.1038/s41598-021-93847-9.

Correspondence and requests for materials should be addressed to K.H.

Reprints and permissions information is available at www.nature.com/reprints. 
Publisher's note Springer Nature remains neutral with regard to jurisdictional claims in published maps and institutional affiliations.

(c) (i) Open Access This article is licensed under a Creative Commons Attribution 4.0 International License, which permits use, sharing, adaptation, distribution and reproduction in any medium or format, as long as you give appropriate credit to the original author(s) and the source, provide a link to the Creative Commons licence, and indicate if changes were made. The images or other third party material in this article are included in the article's Creative Commons licence, unless indicated otherwise in a credit line to the material. If material is not included in the article's Creative Commons licence and your intended use is not permitted by statutory regulation or exceeds the permitted use, you will need to obtain permission directly from the copyright holder. To view a copy of this licence, visit http://creativecommons.org/licenses/by/4.0/.

(C) The Author(s) 2021 